\title{
The sero-prevalence of anti-adenovirus 5 neutralizing antibodies is independent of a chronic hepatitis B carrier state in China
}

\author{
Dao Huang • Marie Hennequi - Alexei Elvachev $\cdot$ Thierry Menguy • \\ Nathalie Silvestre · DeMin Yu - Yue Han • Geneviève Inchauspé • \\ Xinxin Zhang $\cdot$ Ren Zhu
}

Received: 13 May 2014/Accepted: 31 December 2014/Published online: 24 January 2015

(C) The Author(s) 2015. This article is published with open access at Springerlink.com

\begin{abstract}
We investigated the prevalence of neutralizing antibodies (NA) to human Adenovirus (Ad) 5 both in healthy subjects (HS) and Chronic Hepatitis B (CHB) patients in Shanghai. Detection of anti-Ad5 NA (percentage of detection and titers) was similar between HS and CHB patients. A high percentage of subjects harbored no detectable antibodies (32.2\%) while proportion of subjects displaying very high antibody titers was low (4\%). Neither demographic factors (gender, age, health) nor AST/ALT or HBV circulating DNA titers affected detection of Ad5specific NA. These observations pave the ground for development of Ad5-based immunotherapeutics aiming at treating CHB patients in China.
\end{abstract}

Keywords Adenovirus $5 \cdot$ Neutralizing antibodies . Chronic HBV infection

The data haven't been presented at any meeting.

D. Huang $\cdot$ D. Yu $\cdot$ Y. Han $\cdot$ X. Zhang

Department of Infectious Diseases, Institute of Infectious and Respiratory Diseases, Ruijin Hospital, Shanghai JiaoTong University School of Medicine, Shanghai 200025,

People's Republic of China

M. Hennequi - T. Menguy - N. Silvestre

Transgene S.A. Boulevard Gonthier d'Andernach, Parc d'innovation CS80166, 67405 Illkirch-Graffenstaden Cedex, France

A. Elvachev · G. Inchauspé

Transgene S.A. Department of Infectious Diseases, Centre

d'Infectiologie-Bâtiment Domilyon, 69007 Lyon, France

R. Zhu $(\bowtie)$

Transgene Biopharmaceutical Technology (Shanghai) Co., Ltd, Shanghai, People's Republic of China

e-mail: zhu@transgene.fr

$\begin{array}{ll}\text { Abbreviations } \\ \text { Ad } & \text { Adenovirus } \\ \text { ALT } & \text { Alanine transaminase } \\ \text { AST } & \text { Aspartate transaminase } \\ \text { CHB } & \text { Chronic Hepatitis B } \\ \text { AdC } & \text { Chimpanzee adenovirus } \\ \text { HBV } & \text { Hepatitis B virus } \\ \text { HCC } & \text { Hepatocellular carcinoma } \\ \text { HIV } & \text { Human immunodeficiency virus } \\ \text { HS } & \text { Healthy subject } \\ \text { NA } & \text { Neutralizing antibodies } \\ \text { VP } & \text { Viral particle }\end{array}$

Adenovirus (Ad) vectors are extremely potent at inducing cellular-based immune responses to the encoded immunogens. They have been used to develop vaccines against a range of infectious diseases including human immunodeficiency virus (HIV), as well as cancers [1]. Ad serotype 5 has been the most widely used Ad vector because of earlier, historical development, its important safety profile and its remarkable capacity to induce strong, long-lasting and broad T-cell based immune responses, in particular $\mathrm{CD}^{+}$driven ones [2].

We have developed a novel immunotherapeutic TG1050 based on Ad5 that has been engineered to express three major antigens or antigenic domains encoded by the Hepatitis B virus (HBV) genome: the core, polymerase and HBsAg [3]. This novel therapeutics aims at improving treatment of Chronic Hepatitis B (CHB) patients in particular at increasing cure rate. TG1050 has been shown in preclinical studies to induce robust, broad, long-lasting as well as cross-reactive $\mathrm{T}$ cells displaying characteristics similar to those found in patients who resolve infection, together with 
early antiviral activity [3]. Because anti-vector pre-immunity may have some effects on immunity mounted against the vector-encoded immunogens, it is important to document level of vector pre-immunity in the vaccine-targeted population. A number of studies have documented important geographic variations in the sero-prevalence of Ad5 ranging from $40-70 \%$ in the USA and Europe, to $90 \%$ in various regions of Africa and 95\% in Thailand [4]. Recent publications indicate a prevalence in the range of $60-70 \%$ in the Chinese population [5-8]. Because Ad5-based immunotherapies may be of great value in the treatment of CHB in countries displaying elevated prevalence of Hepatitis B, it is important to evaluate whether infection by HBV may influence anti-Ad5 sero-prevalence.

Recently, Jian et al. assessed the prevalence of NA to chimpanzee adenovirus (AdC) serotypes 6 and 7 in healthy adults, CHB patients and patients with primary hepatocellular carcinoma (HCC) in China. They demonstrated that the sero-prevalence rate of AdC6 and AdC7 in CHB patients and HCC patients were much higher than in healthy subjects [9].

We compare here such prevalence of Ad5 NA in both healthy subjects (HS) and CHB patients in subjects living in Shanghai and vicinity.

Two hundred plasma samples from healthy donors, and 204 serum samples from age and gender matched CHB outpatients from Ruijin hospital (Shanghai, China) were collected. Subjects were divided into four age groups (See Table 1A and B). Clinical parameters including HBV viral load, Alanine transaminase (ALT) and Aspartate transaminase (AST) levels were collected.

Ad5-specific NA titers were measured using an adapted luciferase-based virus neutralization assay described by Sprangers et al. [10]. Briefly, diluted samples were mixed with $1.33 \times 10^{7}$ viral particles (VP) of replication defective (E1 and E3 deleted) luciferase-expressing Ad vector (ShenZhao Biotechnology, China), and incubated for 1 hour at room temperature. Five $\times 10^{4}$ A549 target cells were added and incubated at $37{ }^{\circ} \mathrm{C}, 5 \% \mathrm{CO}_{2}$. Following $24 \mathrm{~h}$ incubation, luciferase activity in the cells was quantified using Luciferase Assay System (Promega) with a Microplate Reader (BioTek). The $90 \%$ neutralization sample titer was determined to be the sample dilution which resulted in $90 \%$ neutralization of the Ad-luciferase vector replication as tested on A549 cells. Ranges of titers were defined as $<20,20-200,201-1000$, or $>1000$. They were selected to give a qualitative representation of subjects displaying negative, low, moderate or high preexisting anti-Ad5 immunity, respectively.

Due to the restrictions of sample collection, plasma samples were collected from HS, while serum samples were obtained from CHB patients. To exclude a potential effect of the sample type on the sensitivity of detection of
Ad5 NA, we compared NA levels in serum or plasma of six subjects. As anticipated, no difference was observed (data not shown) supporting comparative analysis using either type of samples.

Sero-prevalence was reported based on age, gender and CHB infection status. In order to analyze impact of these parameters on NA titers, all participants were split into either negative $(<20)$ versus positive $(\geq 20)$ groups or into negative and low titers $(\leq 200)$ versus medium and high titers $(>200)$ groups. The distribution of patients in these groups according to each demographic parameter was tested using the Chi-Square test. Multivariate and univariate logistic regressions were performed to calculate odds ratios (OR) and $95 \%$ confidence interval (CI) in each demographic subgroup. Spearman's correlation coefficients were calculated to analyze correlation between clinical parameters (ALT, ALT and HBV-DNA) and Ad5 NA titers. Analyses were performed with the software SAS 9.3. $\mathrm{P}$-values $<0.05$ were considered significant.

The prevalence of Ad5 NA in plasma samples taken from 200 HS in Shanghai from 20-55 years of age was evaluated. As shown in Table 1A, 63.5\% of HS (127/200) displayed detectable anti-Ad5 NA (titers $\geq 20$ ). Overall, $23 \%(46 / 200)$ and $36.5 \%$ (73/200) of participants displayed low (20-200) or moderate (201-1000) NA titers, respectively, while only $4 \%(8 / 200)$ of individuals displayed high titers $(>1000)$.

Anti-Ad5 sero-prevalence was concomitantly evaluated in 204 age and gender matched CHB outpatients. As shown in Table 1B, $72.06 \%$ of CHB patients (147/204) displayed anti-Ad5-specific NA, a rate similar to that seen in HS. Twenty-six percent (53/204) and $42 \%(86 / 204)$ of patients displayed low (20-200) and moderate (201-1000) levels of NA titers, while only $3.9 \%(8 / 204)$ of them displayed high NA titers $(>1000)$.

When subjects were stratified on the basis of detection or not of Ad5 NA, i.e. whether they displayed titers $<20$ or $\geq 20$, no difference was detected between HS and CHB patients or between different age/gender groups (Table 2A). Similarly, when stratification was made on a broader basis, i.e., between subjects with negative or low titers $\leq 200$ versus medium and high titers $>200$, no statistical differences could be observed within the groups compared (Table 2B).

A global statistical analysis was also performed to evaluate the impact of different demographic parameters including age, gender and CHB infection status on the seroprevalence of anti-Ad5 NA (Table 2). Multivariate and univariate analyses of factors associated with Ad5 NA titers are shown in Table $2 \mathrm{C}$ with associated odds ratios $(95 \% \mathrm{CI})$ and $\mathrm{p}$-values. None of the studied factors had any significant effect on the levels of detected Ad5 NA titers, either in subjects with titers $<20$ versus $\geq 20$ or in subjects with titers $\leq 200$ versus $>200$ (Table 2 ). 
Table 1 Sero-prevalence of Ad5 NA in healthy subjects (A) and CHB patients (B)

\begin{tabular}{|c|c|c|c|c|c|c|}
\hline & \multicolumn{6}{|c|}{ Ad5 NA titer, no. (\%) } \\
\hline & \multirow[t]{2}{*}{$<20$} & \multicolumn{4}{|l|}{$\geq 20$} & \multirow[t]{2}{*}{ Overall } \\
\hline & & 20-200 & 201-1000 & $>1000$ & Total $(\geq 20)$ & \\
\hline \multicolumn{7}{|l|}{ A. } \\
\hline Overall & $73(36.50)$ & $46(23.00)$ & $73(36.50)$ & $8(4.00)$ & $127(63.50)$ & 200 \\
\hline \multicolumn{7}{|c|}{ Age, years } \\
\hline 21-30 & $20(40.00)$ & $14(28.00)$ & $13(26.00)$ & $3(6.00)$ & $30(60.00)$ & 50 \\
\hline $31-40$ & $21(42.00)$ & $9(18.00)$ & $17(34.00)$ & $3(6.00)$ & $29(58.00)$ & 50 \\
\hline $41-50$ & $16(32.00)$ & $8(16.00)$ & $25(50.00)$ & $1(2.00)$ & $34(68.00)$ & 50 \\
\hline $51-55$ & $16(32.00)$ & $15(30.00)$ & $18(36.00)$ & $1(2.00)$ & $34(68.00)$ & 50 \\
\hline \multicolumn{7}{|l|}{ Sex } \\
\hline Male & $37(37.00)$ & $23(23.00)$ & $39(39.00)$ & $1(1.00)$ & $63(63.00)$ & 100 \\
\hline Female & $36(36.00)$ & $23(23.00)$ & $34(34.00)$ & $7(7.00)$ & $64(64.00)$ & 100 \\
\hline \multicolumn{7}{|l|}{ B. } \\
\hline Overall & $57(27.94)$ & $53(25.98)$ & $86(42.16)$ & $8(3.92)$ & $147(72.06)$ & 204 \\
\hline \multicolumn{7}{|c|}{ Age, years } \\
\hline 21-30 & $14(28.00)$ & $9(18.00)$ & $25(50.00)$ & $2(4.00)$ & $36(72.00)$ & 50 \\
\hline $31-40$ & $13(26.00)$ & $10(20.00)$ & $26(52.00)$ & $1(2.00)$ & $37(74.00)$ & 50 \\
\hline $41-50$ & $13(25.49)$ & $20(39.22)$ & $15(29.41)$ & $3(5.88)$ & $38(74.50)$ & 51 \\
\hline $51-55$ & $17(32.08)$ & $14(26.42)$ & $20(37.74)$ & $2(3.77)$ & $36(67.92)$ & 53 \\
\hline \multicolumn{7}{|l|}{ Sex } \\
\hline Male & $32(31.07)$ & $24(23.30)$ & $43(41.75)$ & $4(3.88)$ & $71(68.93)$ & 103 \\
\hline Female & $25(24.75)$ & $29(28.71)$ & $43(42.57)$ & $4(3.96)$ & $76(75.25)$ & 101 \\
\hline
\end{tabular}

We examined whether there was a correlation between clinical parameters such as HBV-DNA load, ALT and AST levels (data not shown) and Ad5 NA titers in CHB patients. Spearman's correlation coefficients were used and showed that levels of Ad5-specific NA titers were not significantly correlated with these clinical parameters (Fig. 1).

Adenoviruses and in particular human Ad 5, have been widely developed as vaccine vehicles because of their high safety profile and their unique capacity to induce strong T-cell based immunity [2]. In the field of HIV vaccine development, high levels of NA to Ad5 have been shown to lower detection of immunogen-specific induced immunity following vaccination and/or to restrict the scope of epitope detection [11, 12]. Contrary observations have been reported more recently in studies of Ad5-based antimalaria and anti-tuberculosis vaccines [13, 14]. Although these later studies were of low size (phase 1), the authors reported a lack of effect of anti-Ad5 pre-immunity on induction of immunogen-specific T-cells, observations that are very encouraging for the development of non-HIV Ad5-based vaccines. In China, at least one Ad5-based immunotherapeutics has successfully reached the market, supporting the value of the Ad5 platform [15]. An international epidemiological study by Mast et al. showed that Ad5 NA titers vary according to geographic location, with titers being higher in non-US and non-European countries
[4]. Recently, detailed studies have been reported on the sero-prevalence of Ad5 NA in China [5-8]. In particular, two studies have shown that $77.4 \%$ of healthy adults in Guangzhou and $72 \%$ of healthy adults in six different regions of China displayed detectable Ad5 NA [ 5,6]. In agreement with the results of these studies and others performed in China [5-7], we observed $63.5 \%$ of seroprevalence to Ad5 NA in 200 HS from Shanghai. In addition, we demonstrated that more than half $(60 \%)$ of the tested HS have negative or low titers of Ad5 NA $(\leq 200)$, while the proportion of high titers individuals $(>1000)$ was very low, only $4 \%$. We confirmed that gender or age difference did not significantly impact the level and titers of Ad5 NA in HS. Because CHB infection is an important and well-recognized medical concern in China [16], efforts are ongoing to develop novel curative treatment regimens. We have developed a novel Ad5-based immunotherapeutic TG1050, which gathers important immunological features found in resolvers [3]. The present study shows that $72.06 \%$ of CHB patients displayed detectable anti-Ad5 NA titers, which, in their levels and distribution, are comparable to those seen in HS ( $p>0.05)$.

We confirmed that a very small number of $\mathrm{CHB}$ patients $(3.92 \%)$ display high NA titers (> 1000). Interestingly, our study did not reveal any correlation with HBV-DNA, ALT, and AST levels and Ad5 NA titers. Overall, the 
Table 2 Distribution of Ad5specific NA titers
*P-value based on chi-square test
A. Distribution of Ad5 NA titers $(<20$ vs $\geq 20$ ) according to clinical status (HS, CHB), age and gender

\begin{tabular}{|c|c|c|c|c|}
\hline & Ad5 NA $t$ & $(\%)$ & & \\
\hline & $<\mathbf{2 0}$ & $\geq 20$ & Overall & P-value* \\
\hline Overall & 130 & 274 & 404 & \\
\hline Clinical status & & & & 0.066 \\
\hline Healthy subjects & $73(56.15)$ & $127(46.35)$ & $200(49.50)$ & \\
\hline CHB subjects & $57(43.85)$ & $147(53.65)$ & $204(50.50)$ & \\
\hline Age, years & & & & 0.841 \\
\hline $20-30$ & $34(26.15)$ & 66 (24.09) & $100(24.75)$ & \\
\hline $31-40$ & $34(26.15)$ & 66 (24.09) & $100(24.75)$ & \\
\hline $41-50$ & $30(23.08)$ & $74(27.01)$ & $104(25.74)$ & \\
\hline $51-55$ & $32(24.62)$ & $68(24.82)$ & $100(24.75)$ & \\
\hline Gender & & & & 0.475 \\
\hline Male & $69(53.08)$ & 135 (49.27) & $204(50.50)$ & \\
\hline Female & $61(46.92)$ & $139(50.72)$ & $200(49.50)$ & \\
\hline
\end{tabular}

B. Distribution of Ad5 NA titers ( $\leq 200$ vs $>200$ ) according to clinical status (HS, CHB), age and gender

\begin{tabular}{|c|c|c|c|c|}
\hline & \multicolumn{4}{|c|}{ Ad5 NA titer, no. (\%) } \\
\hline & $\leq 200$ & $>200$ & Overall & P-value* \\
\hline Overall & 229 & 175 & 404 & \\
\hline Clinical status & & & & 0.258 \\
\hline Healthy subjects & $119(51.97)$ & $81(46.29)$ & $200(49.5)$ & \\
\hline CHB subjects & $110(48.03)$ & $94(53.71)$ & $204(50.50)$ & \\
\hline Age, years & & & & 0.800 \\
\hline $20-30$ & $57(24.89)$ & $43(24.57)$ & $100(24.75)$ & \\
\hline $31-40$ & $53(23.14)$ & $47(26.86)$ & $100(24.75)$ & \\
\hline $41-50$ & $59(25.76)$ & $45(25.71)$ & $104(25.74)$ & \\
\hline $51-55$ & $60(26.20)$ & $40(22.86)$ & $100(24.75)$ & \\
\hline Gender & & & & 0.784 \\
\hline Male & $117(51.09)$ & $87(49.71)$ & $204(50.50)$ & \\
\hline Female & $112(48.91)$ & $88(50.29)$ & $200(49.50)$ & \\
\hline
\end{tabular}

C. Odds ratio and $95 \%$ confidence intervals of Ad5 NA titers ( $<200 \mathrm{vs}>200)$ according to clinical status (HS, CHB), age and gender status, based on univariate and multivariate logistic regression

\begin{tabular}{|c|c|c|c|}
\hline \multirow[b]{2}{*}{ Effect } & \multicolumn{3}{|l|}{ Univariate analysis } \\
\hline & OR $[95 \% \mathrm{CI}]$ & \multicolumn{2}{|l|}{ P-value } \\
\hline \multicolumn{4}{|l|}{ Age } \\
\hline Age (31-40 vs 21-30) & $0.85[0.487-1.486]$ & 0.390 & \\
\hline Age (41-50 vs 21-30) & $0.99[0.568-1.722]$ & 0.994 & \\
\hline Age (51-55 vs 21-30) & $1.13[0.645-1.987]$ & 0.440 & \\
\hline \multicolumn{4}{|l|}{ Sex } \\
\hline Sex (Female vs Male) & $0.95[0.638-1.403]$ & 0.784 & \\
\hline \multicolumn{4}{|l|}{ Subject } \\
\hline \multirow[t]{2}{*}{ Clinical status (CHB vs HS) } & $0.80[0.537-1.182]$ & 0.258 & \\
\hline & \multicolumn{3}{|c|}{ Multivariate analysis } \\
\hline Effect & OR $[95 \% \mathrm{CI}]$ & & P-value \\
\hline Sex (Female vs Male) & $0.95[0.637-1.403]$ & & 0.780 \\
\hline Age (31-40 vs 21-30) & $0.85[0.489-1.486]$ & & 0.386 \\
\hline Age (41-50 vs 21-30) & $0.99[0.570-1.730]$ & & 0.980 \\
\hline Age (51-55 vs 21-30) & $1.13[0.644-1.988]$ & & 0.444 \\
\hline Health (CHB vs HS) & $0.80[0.536-1.181]$ & & 0.256 \\
\hline
\end{tabular}


Fig. 1 Impact of clinical parameters on Ad5 NA titers. NA titers to Ad5 were determined in sera from 204 CHB patients, and the correlation between Ad5 NA titers and ALT (Upper panel) and HBV DNA level (Bottom panel) was analyzed. Levels of Ad5 NA titers, ALT and HBV DNA were represented in logarithmic values $(\log )$. $P$ values (based on Spearman's correlation) are indicated on the graph
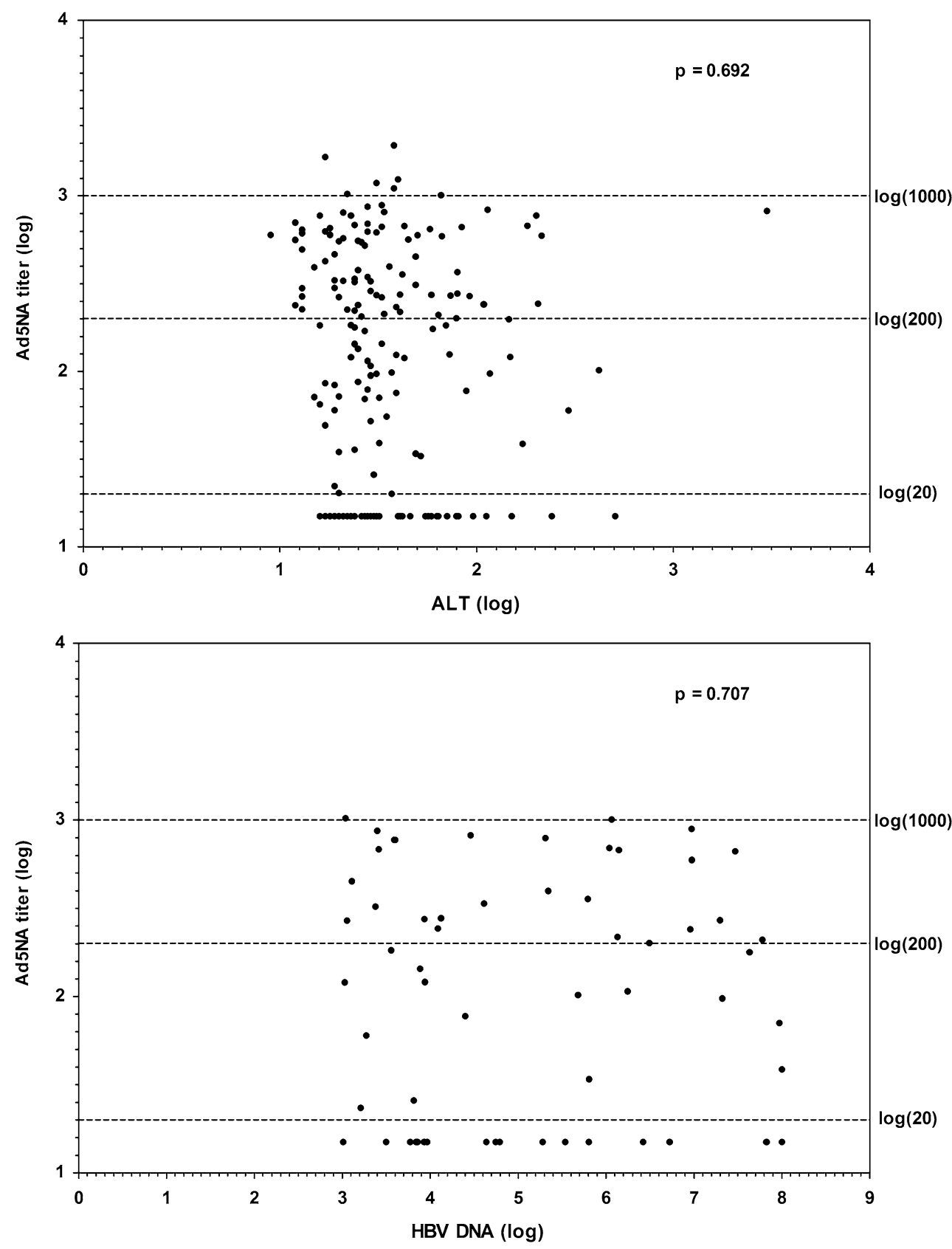

collected data indicate that CHB infection does not influence sero-prevalence and titers of Ad5 NA, implying that chronic infection by HBV does not modulate neither positively nor negatively the development of NA to Ad5. Obviously, it would be of interest to extend our study to other regions in China, beyond the region of Shanghai.

It is difficult to strictly compare studies that have evaluated the presence and titers of Ad5 NA, as assays are not universally standardized and vary from study to study [58]. In our study, the proportion of individuals, either HS or CHB patients in Shanghai, displaying high titers of Ad5 NA, was lower than that reported by Yu et al. A number of reasons may explain the differences observed. Our studied population was likely different from that studied by $\mathrm{Yu}$ et al. [6], (different geographic location) and, for example, may have included more migrant population (Shanghai is known to have a large migrant population). It would be of obvious interest to expand our analysis beyond the area of Shanghai in order to generalize our observations to major cities in China. In addition, in our study, Ad5-specific NA titers were measured using chemiluminescence-based NA test (CLNT), which has higher sensitivity than the fluorescence-based NA (FRNT) assay reported by Liu et al. [8]. Our evaluation was primarily based on $90 \%$ neutralization and 
not $50 \%$ as often reported. Even when similar CLNT tests are used [7, 9], different protocols (such as virus concentration, cell density, etc.), use of different luminometers, and different definitions of neutralization titers may all influence the quality and sensitivity of detection assays, rendering comparisons delicate to perform.

In conclusion, our study shows that the sero-prevalence and titer of Ad5 NA are not affected by infection with $\mathrm{HBV}$, an observation supporting the development of TG1050 in Chinese CHB infected patients.

Acknowledgements This work was supported by Transgene S.A. The authors declare that they have no conflict of interest. We thank the staff in the clinical virology research unit from Ruijin Hospital, who helped with sample collection. We are grateful to P. Martin for critical reading of the manuscript and for constructive discussion through the course of this work

Conflict of interest Authors have no commercial or other association that might pose a conflict of interest.

Open Access This article is distributed under the terms of the Creative Commons Attribution License which permits any use, distribution, and reproduction in any medium, provided the original author(s) and the source are credited.

\section{Reference}

1. Rollier CS, Reyes-Sandoval A, Cottingham MG, Ewer K, Hill AV (2011) Viral vectors as vaccine platforms: deployment in sight. Curr Opin Immunol 23(3):377-382. doi:10.1016/j.coi. 2011.03.006

2. Bassett JD, Swift SL, Bramson JL (2011) Optimizing vaccineinduced CD8(+) T-cell immunity: focus on recombinant adenovirus vectors. Expert Rev Vaccines 10(9):1307-1319. doi:10. 1586/erv. 11.88

3. Martin P, Dubois C, Jacquier E, Evlachev A, Boukhebza H, Dion S, Mancini-Bourgine M, Godon O, Findeli A, Schlesinger Y, Brandely R, Marchand JB, Menguy T, Silvestre N, Schirmbeck R, Michel M, Inchauspe G (2013) A multivalent adenovirusbased immunotherapeutic for treatment of chronic hepatitis B induces broad, robust and polyfunctional $\mathrm{T}$ cells in naive and HBV tolerant mice. J Hepatol 58:S55-S56

4. Mast TC, Kierstead L, Gupta SB, Nikas AA, Kallas EG, Novitsky V, Mbewe B, Pitisuttithum P, Schechter M, Vardas E, Wolfe ND, Aste-Amezaga M, Casimiro DR, Coplan P, Straus WL, Shiver JW (2010) International epidemiology of human pre-existing adenovirus (Ad) type-5, type-6, type-26 and type-36 neutralizing antibodies: correlates of high Ad5 titers and implications for potential HIV vaccine trials. Vaccine 28(4):950-957. doi:10. 1016/j.vaccine. 2009.10 .145

5. Sun C, Zhang Y, Feng L, Pan W, Zhang M, Hong Z, Ma X, Chen $X$, Chen L (2011) Epidemiology of adenovirus type 5 neutralizing antibodies in healthy people and AIDS patients in Guangzhou, southern China. Vaccine 29(22):3837-3841. doi:10.1016/j. vaccine.2011.03.042

6. Yu B, Zhou Y, Wu H, Wang Z, Zhan Y, Feng X, Geng R, Wu Y, Kong W, Yu X (2012) Seroprevalence of neutralizing antibodies to human adenovirus type 5 in healthy adults in China. J Med Virol 84(9):1408-1414. doi:10.1002/jmv.23325
7. Zhang S, Huang W, Zhou X, Zhao Q, Wang Q, Jia B (2013) Seroprevalence of neutralizing antibodies to human adenoviruses type- 5 and type- 26 and chimpanzee adenovirus type- 68 in healthy Chinese adults. J Med Virol 85(6):1077-1084. doi:10.1002/jmv. 23546

8. Liu Q, Nie J, Huang W, Meng S, Yuan B, Gao D, Xu X, Wang Y (2012) Comparison of two high-throughput assays for quantification of adenovirus type 5 neutralizing antibodies in a population of donors in China. PLoS one 7(5):e37532. doi:10.1371/ journal.pone.0037532

9. Jian L, Zhao Q, Zhang S, Huang W, Xiong Y, Zhou X, Jia B (2014) The prevalence of neutralising antibodies to chimpanzee adenovirus type 6 and type 7 in healthy adult volunteers, patients with chronic hepatitis B and patients with primary hepatocellular carcinoma in China. Arch Virol 159(3):465-470. doi:10.1007/ s00705-013-1828-y

10. Sprangers MC, Lakhai W, Koudstaal W, Verhoeven M, Koel BF, Vogels R, Goudsmit J, Havenga MJ, Kostense S (2003) Quantifying adenovirus-neutralizing antibodies by luciferase transgene detection: addressing preexisting immunity to vaccine and gene therapy vectors. J Clin Microbiol 41(11):5046-5052

11. Harro CD, Robertson MN, Lally MA, O'Neill LD, Edupuganti S, Goepfert PA, Mulligan MJ, Priddy FH, Dubey SA, Kierstead LS, Sun X, Casimiro DR, DiNubile MJ, Shiver JW, Leavitt RY, Mehrotra DV (2009) Safety and immunogenicity of adenovirusvectored near-consensus HIV type 1 clade B gag vaccines in healthy adults. AIDS Res Human Retroviruses 25(1):103-114. doi:10.1089/aid.2008.0212

12. Buchbinder SP, Mehrotra DV, Duerr A, Fitzgerald DW, Mogg R, Li D, Gilbert PB, Lama JR, Marmor M, del Rio C, McElrath MJ, Casimiro DR, Gottesdiener KM, Chodakewitz JA, Corey L, Robertson MN (2008) Efficacy assessment of a cell-mediated immunity HIV-1 vaccine (the Step Study): a double-blind, randomised, placebo-controlled, test-of-concept trial. The Lancet 372(9653):1881-1893. doi:10.1016/s0140-6736(08)61591-3

13. Tamminga C, Sedegah M, Regis D, Chuang I, Epstein JE, Spring $\mathrm{M}$, Mendoza-Silveiras J, McGrath S, Maiolatesi S, Reyes S, Steinbeiss V, Fedders C, Smith K, House B, Ganeshan H, Lejano J, Abot E, Banania GJ, Sayo R, Farooq F, Belmonte M, Murphy J, Komisar J, Williams J, Shi M, Brambilla D, Manohar N, Richie NO, Wood C, Limbach K, Patterson NB, Bruder JT, Doolan DL, King CR, Diggs C, Soisson L, Carucci D, Levine G, Dutta S, Hollingdale MR, Ockenhouse CF, Richie TL (2011) Adenovirus5 -vectored $P$. falciparum vaccine expressing CSP and AMA1. Part B: safety, immunogenicity and protective efficacy of the CSP component. PloS One 6(10):e25868. doi:10.1371/journal.pone. 0025868

14. Smaill F, Jeyanathan M, Smieja M, Medina MF, Thanthrige-Don N, Zganiacz A, Yin C, Heriazon A, Damjanovic D, Puri L, Hamid J, Xie F, Foley R, Bramson J, Gauldie J, Xing Z (2013) A human type 5 adenovirus-based tuberculosis vaccine induces robust $\mathrm{T}$ cell responses in humans despite preexisting anti-adenovirus immunity. Sci Transl Med 5(205):205ra134. doi:10.1126/sci translmed.3006843

15. Garber K (2006) China approves world's first oncolytic virus therapy for cancer treatment. J Natl Cancer Inst 98(5):298-300. doi:10.1093/jnci/djj111

16. Liang X, Bi S, Yang W, Wang L, Cui G, Cui F, Zhang Y, Liu J, Gong X, Chen Y, Wang F, Zheng H, Guo J, Jia Z, Ma J, Wang H, Luo H, Li L, Jin S, Hadler SC, Wang Y (2009) Epidemiological serosurvey of hepatitis B in China-declining HBV prevalence due to hepatitis B vaccination. Vaccine 27(47):6550-6557. doi:10.1016/j.vaccine.2009.08.048 